Schulich School of Law, Dalhousie University

Schulich Law Scholars

Articles, Book Chapters, \& Popular Press

Faculty Scholarship

2014

\title{
The Role of the UNFCCC Regime in Ensuring Effective Adaptation in Developing Countries: Lessons from Bangladesh
}

\author{
Meinhard Doelle \\ Dalhousie University Schulich School of Law, meinhard.doelle@dal.ca \\ Steven Evans \\ Dalhousie University Schulich School of Law \\ Tony George Puthucherril
}

Follow this and additional works at: https://digitalcommons.schulichlaw.dal.ca/scholarly_works

Part of the Environmental Law Commons

\section{Recommended Citation}

Meinhard Doelle, Steven Evans \& Tony George Puthucherril, "The Role of the UNFCCC Regime in Ensuring Effective Adaptation in Developing Countries: Lessons from Bangladesh" (2014) 4 Climate L 327.

This Article is brought to you for free and open access by the Faculty Scholarship at Schulich Law Scholars. It has been accepted for inclusion in Articles, Book Chapters, \& Popular Press by an authorized administrator of Schulich Law Scholars. For more information, please contact hannah.steeves@dal.ca. 
The Role of the UNFCCC Regime in Ensuring Effective Adaptation in Developing Countries: Lessons from Bangladesh

- Meinhard Doelle, Professor of Law and Director, Marine \& Environmental Law Institute, Schulich School of Law, Halifax, NS, Canada

- Steven Evans, JD Candidate (2014), Schulich School of Law

- Tony George Puthucherril, PHD (2013), Schulich School of Law

\section{INTRODUCTION}

It has been two decades since the world's universal endorsement of the United Nations Framework Convention on Climate Change. What began primarily as an agreement directed at stabilizing atmospheric greenhouse gases at a safe level has since expanded its focus to recognize that some of the negative impacts of climate change are already being felt, especially in the developing world, and that developed countries have an obligation to provide concrete and significant adaptation support to developing countries. The past decade in particular has seen the creation of a number of initiatives on adaptation, key among them decisions in Bali in 2007 and Cancun in 2010 that have placed adaptation at least formally at the same level of priority as mitigation. ${ }^{1}$

How effective has the UNFCCC become at supporting adaptation in developing countries, and how could it do better? This is not an easy question to answer. Adaptation occurs locally in response to a wide variety of impacts, many of which are uncertain and future-oriented. It is more difficult to measure the effectiveness of an adaptation program than mitigation. With respect to mitigation, the UNFCCC has so far clearly failed to adequately reduce the level of greenhouse gas emissions, leaving developing countries more vulnerable than ever. ${ }^{2}$

The goal of this article is to explore climate change adaptation efforts in Bangladesh, to assess the effectiveness of the UNFCCC in assisting developing countries such as Bangladesh in their efforts to adapt, and to offer recommendations for negotiators of the future climate regime. Bangladesh was chosen as a case study because it is not only one of the world's most vulnerable countries to climate change, but it has also been one of the most active on adaptation, both within and outside of the UNFCCC. Because it has been so active, understanding the adaptation challenge in Bangladesh may offer insights into the potential role of the UNFCCC adaptation regime in addressing the adaptation needs of other developing countries.

Of course, Bangladesh is only one of many developing countries, each with their own unique set of circumstances and adaptation needs. Nevertheless, the article does serve to illustrate the extent to which the current approach under the UNFCCC is likely to serve Bangladesh well in its efforts to improve its adaptive capacity and its climate resilience. The article draws some preliminary conclusions about the

1 For more details, see UNFCCC, Adaptation Overview, online: UNFCCC $<$ http://unfccc.int/adaptation/ items/7623.php>.

2 See generally UNEP, The Emissions Gap Report 2013: A UNEP Synthesis Report (Nairobi: UNEP, 2013). 
UNFCCC approach, while fully recognizing that such conclusions would have to be verified through similar case studies of many other developing countries. It also means that the article's recommendations focus on high level questions about the UNFCCC's approach to adaptation, as more specific conclusions based on the Bangladesh case study would be less likely to be confirmed through similar case studies of other countries.

The article is divided into the following sections. Section 1 provides an overview of adaptation efforts under the current UNFCCC regime. Section 2 summarizes the state of discussions with respect to the post-2020 approach to adaptation. Section 3 looks at adaptation on the ground in Bangladesh. Section 4 offers recommendations for how the UNFCCC can improve its support for Bangladesh, followed by some concluding comments.

\section{ADAPTATION UNDER THE UNFCCC}

The UNFCCC includes a surprising number of general obligations with respect to adaptation. While the focus at the time was clearly on mitigation, it is important to note the relatively strong language on adaptation in the Convention. Under Article 4(1), all parties are to devise national and, where appropriate, regional adaptation programs, and to cooperate in preparing for adaptation to climate change. ${ }^{3}$ All parties commit to taking climate change considerations into account in their government policies (known as "mainstreaming"). ${ }^{4}$ Article 4(3) calls on developed country parties to provide new and additional funding to help developing country parties meet these obligations. ${ }^{5}$ Article 4(4) commits developed country parties to "assist the developing country Parties that are particularly vulnerable to the adverse effects of climate change in meeting costs of adaptation to those adverse effects". ${ }^{6}$ Article 4(8) expands further on the commitment to provide funding, insurance, and technology to meet the needs of developing countries, and especially those most vulnerable to the impacts of climate change. ${ }^{7}$ Article 4(5) requires developed countries to "take all practicable steps to promote, facilitate and finance, as appropriate, the transfer of, or access to, environmentally sound technologies and know-how to other Parties, particularly developing country Parties, to enable them to implement the provisions of the Convention". Finally, Article 4(9) commits parties to take full account of the "specific needs and special situations" of least developed countries (LDCs) with regard to funding and technology. ${ }^{8}$

The primary focus of the Kyoto Protocol is the mitigation of global greenhouse gas emissions, however, it also contains provisions to support adaptation in developing countries. Article 10(b) of the Protocol commits all parties to "formulate, implement, publish and regularly update national and, where appropriate, regional programmes containing measures to mitigate climate change and measures to

\footnotetext{
UNFCCC 1992, United Nations Framework Convention on Climate Change, online: UNFCCC, $<$ www.unfecc.int>, at art. 4(1) (hereinafter UNFCCC 1992).

Ibid.

Ibid., at art. 4(3).

Ibid., at art. 4(4).

Ibid., at art. 4(8).

Ibid., at art. 4(9).
} 
facilitate adequate adaptation to climate change". 9 Article 10 (c) calls upon parties to take "all practicable steps to promote, facilitate and finance, as appropriate, the transfer of, or access to, environmentally sound technologies, know-how, practices and processes pertinent to climate change, in particular to developing countries, including the formulation of policies and programmes for the effective transfer of environmentally sound technologies that are publicly owned or in the public domain and the creation of an enabling environment for the private sector, to promote and enhance the transfer of, and access to, environmentally sound technologies". ${ }^{10}$ Article 12(8) provides that a share of the proceeds from the Clean Development Mechanism (CDM) go towards assisting particularly vulnerable developing country parties meet the costs of adaptation. ${ }^{11}$

There are two sub-themes that can be drawn from these provisions of the UNFCCC and its Kyoto Protocol: the issue of financing of adaptation actions and issues related to accessing adaptation technology. In fact, all climate change adaptation efforts under the UNFCCC to date deal with finance and technology in some form (materials, equipment or knowledge). ${ }^{12}$ These two adaptation issues have evolved through decisions at key Conferences of the Parties. In 2000, at COP 6 in Bonn, the Adaptation Fund was created to finance concrete adaptation projects and programs in developing countries that are parties to the Kyoto Protocol. ${ }^{13}$ Funding for the Adaptation Fund comes primarily from a 2 percent levy on the sale of Certified Emission Reductions (CERs) derived from the Clean Development Mechanism. Additional funding comes from voluntary donations, and, as decided at COP 18 in 2012, the extension of the 2 percent levy to Joint Implementation (JI) projects and international emissions trading (ET). ${ }^{14}$

In 2001, at COP 7 in Marrakesh, parties established the LDC Work Programme. ${ }^{15}$ This programme reflects the special situation of LDCs acknowledged under Article 4(9) of the Convention. ${ }^{16}$ It supports capacity building in LDCs, including the preparation and implementation of national adaptation programmes of action (NAPAs). ${ }^{17}$ The purpose of NAPAs is to have LDCs "identify priority activities that respond to their urgent and immediate needs with regard to climate

9 UNFCCC, 1998, Kyoto Protocol to the United Nations Framework Convention on Climate Change, online: UNFCCC, at art. 10(b) <www.unfccc.int> (hereinafter UNFCCC 1998).

10 Ibid., at art. 10(c).

11 Ibid., at art. 12(8).

12 See generally UNFCCC, Technologies for Adaptation to Climate Change (Bonn, Germany: Climate Change Secretariat (UNFCCC), 2006) (hereinafter UNFCCC, Technologies for Adaptation).

13 Report of the Conference of the Parties on the First Part of its Sixth Session, Held at The Hague from 13 to 25 November 2000: Addendum: Part Two: Action Taken by the Conference of the Parties at the First Part of its Sixth Session, FCCC/CP/2000/5/Add.2, (1/CP.6, UNFCCC, 2001), at 5.

14 Report of the Conference of the Parties Serving as the Meeting of the Parties to the Kyoto Protocol on its Eighth Session, Held in Doha from 26 November to 8 December 2012: Addendum: Part Two: Action Taken by the Conference of the Parties Serving as the Meeting of the Parties to the Kyoto Protocol at its Eighth Session, FCCC/KP/CMP/2012/13/Add.1, (1/CMP.8, UNFCCC, 2013), at para. 21.

15 Report of the Conference of the Parties on its Seventh Session, Held at Marrakesh from 29 October to 10 November 2001. Addendum. Part Two: Action Taken by the Conference of the Parties. Volume I, FCCC/CP/2001/13/Add.1, (5/CP.7, UNFCCC, 2002), at para. 11 (hereinafter UNFCCC 2001 Report).

16 Ibid.

17 Ibid. 
change". ${ }^{18}$ In order to fund the elements of the LDC Work Programme, including NAPAs, parties at COP 7 created the Least Developed Countries Fund (LDCF). ${ }^{19}$ At the same conference, parties also established the Special Climate Change Fund (SCCF) to provide funding for projects relating to a number of different areas, including adaptation. ${ }^{20}$ Both the LDCF and the SCCF are managed by the Global Environment Facility (GEF) and depend on voluntary contributions from donors.

At COP 11 in 2005, the Nairobi Work Programme was created. The Programme, undertaken under the UNFCCC's Subsidiary Body for Scientific and Technological Advice (SBSTA), has the objective of assisting all parties, in particular developing country parties, to "improve their understanding and assessment of impacts, vulnerability and adaptation to climate change" and to "make informed decisions on practical adaptation actions and measures to respond to climate change on a sound scientific, technical and socio-economic basis, taking into account current and future climate change and variability". ${ }^{21}$ The Programme became operational in 2006.

At COP 16 in 2010, parties adopted the Cancun Adaptation Framework (CAF), which resulted from three years of negotiations following the adoption of the Bali Action Plan. The CAF affirms that adaptation requires the same level of priority as mitigation and commits parties to enhanced action on adaptation. ${ }^{22}$ This includes the planning, prioritization, and implementation of adaptation actions; the undertaking of impact, vulnerability and adaptation assessments; the strengthening of institutional capacities and knowledge systems; and the building of resilience in socio-economic and ecological systems. ${ }^{23}$ The CAF also established an Adaptation Committee to promote coherent enhanced action on adaptation, and introduced a process to enable LDCs to create National Adaptation Plans (NAPs) as a means of identifying and addressing medium- and long-term adaptation needs ${ }^{24}$.

Parties in Cancun furthermore agreed to establish the Green Climate Fund (GCF), with developed country parties committing to jointly mobilize US\$100 billion per year by 2020 to address the needs of developing countries. ${ }^{25}$ The funding is to be used for mitigation, adaptation, technology development and transfer, and capacity building activities. ${ }^{26} \mathrm{GCF}$ funds are to be "new and additional" and raised from public and private, bilateral and multilateral, and alternative sources. ${ }^{27}$ Developed country parties also committed to providing US\$30 billion in "fast start" climate financing by

18 UNFCCC, Chronological Evolution of the LDC Work Programme and Introduction to the Concept of NAPA, online: UNFCCC <www.unfccc.int $>$.

19 UNFCCC 2001 Report, supra note 15, at para. 12.

20 Report of the Conference of the Parties on its Seventh Session, Held at Marrakesh from 29 October to 10 November 2001. Addendum. Part Two: Action Taken by the Conference of the Parties. Volume I, FCCC/CP/2001/13/Add.1, (7/CP.7, UNFCCC, 2002).

21 See generally Report of the Conference of the Parties on its Eleventh Session, Held at Montreal from 28 November to 10 December 2005: Addendum: Part Two: Action Taken by the Conference of the Parties at its Eleventh Session, FCCC/CP/2005/5/Add.1, (2/CP.11, UNFCCC, 2006), at 5.

22 Report of the Conference of the Parties on its Sixteenth Session, Held in Cancun from 29 November to 10 December 2010: Addendum: Part Two: Action Taken by the Conference of the Parties at its Sixteenth Session, FCCC/CP/2010/7/Add.1, (1/CP.16, UNFCCC, 2011), at 1.

23 Ibid.

24 Ibid., at para. 15.

25 Ibid., at para. 98.

26 Ibid., at para. 95.

27 Ibid., at paras. 95, 99 and 101 . 
2012, with a balanced allocation between adaptation for "the most vulnerable developing countries, such as the least developed countries, small island developing States and Africa", and mitigation. ${ }^{28}$

At Doha (COP 18) in 2012, parties approved a three-year work plan for the Adaptation Committee, as well as the National Adaptation Plan technical guidelines. ${ }^{29}$ The Adaptation Committee's work plan includes efforts to increase coherence and find synergies in the adaptation work of both Convention and non-Convention bodies, and the provision of knowledge and technical support for developing countries engaged in adaptation planning and implementation. ${ }^{30}$ The Adaptation Committee also supports the creation of NAPs by LDC and non-LDC developing countries. ${ }^{31}$

Finally, in Doha the Parties agreed to establish at COP 19 "institutional arrangements, such as an international mechanism" to address loss and damage resulting from climate change impacts in developing countries that are "particularly vulnerable to the adverse effects of climate change". ${ }^{32}$ This resulted in the Warsaw international mechanism for loss and damage under the Cancun Adaptation Framework, agreed to in $2013 .{ }^{33}$ The aim of the Warsaw international mechanism is to promote "the implementation of approaches to address loss and damage associated with the adverse effects of climate change", for example, by enhancing knowledge, increasing coordination among stakeholders and enhancing action and support (including finance and technology). ${ }^{34}$ However, there is still no definition of loss and damage under the UNFCCC and the relationship to adaptation is not entirely clear. Nishat et al. define loss and damage as "current or future negative impacts of climate change that will not be addressed by adaptation efforts". 35

COP decisions have time and again stressed the importance of the development and transfer of technologies. Initially, to enhance the implementation of Article 4.5 of the UNFCCC, the parties agreed to work together on a set of technology transfer activities. This resulted in the technology transfer framework ${ }^{36}$, which identifies five key themes and areas for meaningful and effective actions, namely, technology needs

28 Ibid., at para. 95.

29 Report of the Conference of the Parties on its Eighteenth Session, Held in Doha from 26 November to 8 December 2012: Addendum: Part Two: Action Taken by the Conference of the Parties at its Eighteenth Session, FCCC/CP/2012/8/Add.1, (1/CP.18, UNFCCC, 2013), at 3. The development of the technical guidelines were developed by the Least Developed Countries Expert Group (LEG).

30 Adaptation Committee, Three-year Workplan of the Adaptation Committee, online: UNFCCC, $<$ unfecc.int $>$.

31 Least Developed Countries Expert Group, National Adaptation Plans: Technical Guidelines for the National Adaptation Plan Process (Bonn, Germany: UNFCCC Secretariat, 2012).

32 Report of the Conference of the Parties on its Eighteenth Session, Held in Doha from 26 November to 8 December 2012: Addendum: Part Two: Action Taken by the Conference of the Parties at its Eighteenth Session, FCCC/CP/2012/8/Add.1, (3/CP.18, UNFCCC, 2013), at 21.

33 Report of the Conference of the Parties on its Nineteenth Session, Held in Warsaw from 11 to 23 November 2013: Addendum: Part Two: Action Taken by the Conference of the Parties at its Nineteenth Session, FCCC/CP/2013/10/Add.1, (2/CP.19, UNFCCC, 2014), at 6.

34 Ibid.

35 Ainun Nishat, Nandan Mukherjee, Erin Roberts, and Anna Hasemann, 'Loss \& Damage: A Range of Approaches to Address Loss and Damage from Climate Change Impacts in Bangladesh (Bonn, Germany: Germanwatch, 2013), at 7.

36 UNFCCC, Decision 4/CP.7, 'Framework for Meaningful and Effective Actions to Enhance the Implementation of Article 4, Paragraph 5, of the Convention', FCCC/CP/2001/13/Add.1, (2002), at 24. 
and needs assessments, technology information, enabling environments, capacity building, and mechanisms for technology transfer. It also provided for the creation of an expert group on technology transfer, which seeks to analyse and identify ways to facilitate and advance technology transfer activities. ${ }^{37}$ The Cancun Agreements led to the establishment of a Technology Mechanism with two components, namely, the Technology Executive Committee an the Climate Technology Centre and Network. The Technology Executive Committee identifies technology needs, recommends guidance on priorities, recommends actions to overcome barriers and catalyzes the development and use of technology action plans. The Climate Technology Centre and Network has as its mission to "stimulate technology cooperation and ... enhance the development and transfer of technologies and to assist developing country Parties at their request, consistent with their respective capabilities and national circumstances and priorities." 38

The Global Environment Facility also plays a role in effectuating transfers of environmentally sound technologies to developing countries. Of the two UNFCCC funds administered by the GEF, the SCCF specifically aims to support the transfer of environmentally sound technologies to developing countries. Technology transfer also occurs under the LDCF. ${ }^{39}$ At the 13 th COP, the GEF was called upon to develop a program to promote investment in technology transfer so as to help developing countries to adopt environmentally sound technologies (ESTs). In 2008, the GEF Council and the LDCF/SCCF Council discussed and approved the Strategic Program on Technology Transfer. Subsequently, the 14th session of the COP welcomed the GEF's Strategic Program on Technology Transfer, renaming it the Poznan Strategic Program on Technology Transfer. The Poznan Strategic Programme on Technology Transfer is seen as an important development towards scaling up investment in technology transfer and help developing countries access environmentally sound technologies. ${ }^{40}$ The United Nations Environment Programme (UNEP) also plays a role in facilitating technology development and transfer through its technology needs assessment project, which is designed to assist developing country Parties in determining their technology priorities for climate change mitigation and adaptation.

\section{THE STATE OF NEGOTIATIONS ON ADAPTATION}

There is no question that adaptation has now become a core element of the Convention. Over the past decade, the number of bodies and processes related to adaptation has grown rapidly. Negotiators are now considering how adaptation should be addressed under the post-2020 climate regime. With the Adaptation Committee and NAP process both in their early stages, and the Green Climate Fund under development, the architecture envisioned under the Cancun Adaptation Framework is gradually coming into place. To some extent, this has left Parties in a state of "wait

37 UNFCCC, Decision 4/CP.7, 'Terms of Reference of the Expert Group on Technology Transfer', $\mathrm{FCCC} / \mathrm{CP} / 2001 / 13 /$ Add.1, (2002), at 31.

38 UNFCCC, Climate Technology Centre and Network (CTCN), online: UNFCCC <http://unfccc.int /2860.php>.

39 See generally GEF, 'Technology Transfer for Climate Change', in Fact Sheets about the GEF (June, 2009).

40 GEF, Poznan Strategic Program on Technology Transfer, online: GEF $<$ http://www.thegef.org/gef/ho me $>$. 
and see". How the Framework does or does not deliver will clearly influence the directions that negotiations on a new climate deal will take.

Despite the progress made so far, the glaring lack of adequate and predictable funding available for adaptation in developing countries remains a serious obstacle. The funding required to adequately support adaptation has been estimated at between US $\$ 70$ billion and US\$100 billion per year. ${ }^{41}$ So far, the UNFCCC's financial mechanisms have provided just a small fraction of this. The Least Developed Countries Fund and the Special Climate Change Fund have collectively raised US\$863 million and disbursed US\$244 million, ${ }^{42}$ while the Adaptation Fund has generated US $\$ 325$ million and disbursed $\$ 58$ million. ${ }^{43}$ Of the roughly $\$ 30$ billion in "new and additional" Fast Start Finance that was provided by developed countries over 2010-2012, only a small share was directed to support adaptation, with the bulk allotted for mitigation activities. ${ }^{44}$ While developing countries in Doha demanded that developed countries commit to scaled up climate finance for the pre-2020 period, developed countries only agreed to maintain current funding levels. ${ }^{45}$

The UNFCCC established a work programme on long-term finance at COP 17 to make progress on scaling up the funding available for developing countries. ${ }^{46} \mathrm{In}$ the work programme's 2012 report, the programme co-chairs state that "substantial increases in financial resources are needed in order to help developing countries to limit and reduce GHG emissions, and to adapt to the impacts of climate change", and recommend a political process focused on "sources and options for mobilizing climate finance in the short, medium and long terms". ${ }^{47}$ Additionally, they call for increased clarity and predictability in the delivery of climate finance, strengthened tracking of climate finance, improved identification of adaptation needs, enhanced enabling environments in developing countries and the establishment of a regular forum on climate finance. $^{48}$

Various options for generating new climate finance have been proposed and studied, most notably by the UN Secretary-General's high-level advisory group on climate change financing (AGF). ${ }^{49}$ The AGF identified options that include the auctioning of emission allowances, a global carbon tax, an emissions trading levy and

41 Urvashi Narain, Sergio Margulis and Timothy Essam, 'Estimating Costs of Adaptation to Climate Change', 11(3) Climate Policy 1001 (2011), at 1007.

42 Climate Funds Update, Climate Fund Profiles, online: Climate Funds Update, <http://www.c limatefundsupdate.org/> (hereinafter Climate Funds Update).

43 The World Bank, 2013, Trustee Presentation: Update on Status of Resources and CER Monetization, Adaptation Fund Trustee, The World Bank, AFB/B.21/Inf.4 (2013).

${ }^{44}$ Taryn Fransen and Smita Nakhooda, '5 Insights from Developed Countries' Fast-Start Finance Contributions', World Resources Institute Blog, 11 June 2013, online: WRI <http://www.wri.org/>.

45 Jennifer Morgan, 'Reflections on COP 18 in Doha: Negotiators Made Only Incremental Progress', World Resources Institute Blog, 14 December 2012, online: WRI <http://www.wri.org/>.

46 Report of the Conference of the Parties on its Seventeenth Session, Held in Durban from 28 November to 11 December 2011: Addendum. Part Two: Action Taken by the Conference of the Parties at its Seventeenth Session, FCCC/CP/2011/9/Add.1, (2/CP.17, UNFCCC, 2012), at 4.

47 Report on the Workshops of the Work Programme on Long-term Finance: Note by the Co-chairs, UN Framework Convention on Climate Change, Conference of the Parties, 18th Sess., Item 11(a) of the Provisional Agenda, FCCC/CP/2012/3 (2012), at paras. 8, 10 (hereinafter $L T F$ ).

48 Ibid., at paras. 10-14.

49 See generally UN, Report of the Secretary-General's High-level Advisory Group on Climate Change Financing (New York: UN, 2010) (hereinafter $A G F$ ). 
a tax on international shipping and air travel. ${ }^{50}$ The work programme on long-term finance co-chairs acknowledge these proposals, yet stop short of making specific recommendations. Instead, they note that no single source of climate finance identified would generate sufficient financial resources and that a combination of sources is likely to be required. ${ }^{51}$ Such a combination, the co-chairs note, "should be subject to further international and national analysis and discussion., ${ }^{, 52}$

The work programme on long-term finance was extended at COP 18 until the end of 2013, with a mandate to "inform developed country Parties in their efforts to identify pathways for mobilizing scaled-up climate finance to USD 100 billion per year by 2020".53 Other UNFCCC processes and bodies involved in trying to scale up climate finance include the Standing Committee on Finance (responsible for the financial mechanism of the Convention), the Green Climate Fund and the Adaptation Fund. Of these, only the Adaptation Fund has support for adaptation as its primary mandate.

While adaptation is clearly receiving more attention at the negotiations than a decade ago, it still lags behind mitigation in financial resources. Adaptation funding has been criticized by developing countries as "piecemeal" and not matched to the needs of the most vulnerable countries. ${ }^{54}$ For this reason, developing countries are seeking assurances that in a new climate deal a "significant proportion" "balanced allocation" of climate funds be allocated to adaptation. ${ }^{56}$

As far as the technology aspect of adaptation is concerned, the emerging regime will be challenged to resolve issues relating to intellectual property rights and to provide for increased action on technology development and transfer, including research and development, demonstration, deployment, and diffusion of technology. Issues relating to financing such technology transfers will also have to be resolved in the new regime. To date, much of the debate in this area has related to mitigation technology. While there may be some opportunities for integrated solutions, technologies for adaptation largely differ from those needed for mitigation. ${ }^{57}$ It is therefore essential that any emerging regime on climate change consider environmentally sound technologies for adaptation as a discrete class.

\section{ADAPTATION IN BANGLADESH}

50 Ibid.

51 LTF, supra note 47 , at para. 21.

52 Ibid.

53 Report of the Conference of the Parties on its Eighteenth Session, Held in Doha from 26 November to 8 December 2012: Addendum: Part Two: Action Taken by the Conference of the Parties at its Eighteenth Session, FCCC/CP/2012/8/Add.1, (4/CP.18, UNFCCC, 2013), at 25.

54 Long-term Finance (COP), Submission by the Republic of Nauru on Behalf of the Alliance of Small Island States (AOSIS): Views from Parties on Long-term Finance, online: UNFCCC $<\mathrm{https}$ ://unfcc c.int/2860.php>.

55 Ibid.

56 Submission by Nepal on behalf of the Group of the Least Developed Countries on Experiences on the Application of Guidelines for the Formulation of National Adaptation Plan Process for Least Developed Countries (8 February 2013), online: UNFCCC <http://unfccc.int/2860.php>.

57 UNFCCC, Technologies for Adaptation, supra note 12, at 10-11. 
Climate change poses a threat to all countries, but nowhere is the threat greater than in LDCs such as Bangladesh. Developing countries, with their low resilience and low adaptive capacities, their typically warmer baseline climates, high reliance on agriculture and increased exposure to extreme events, are expected to suffer the most. ${ }^{58}$ This is the case despite the fact that the world's poorest nations have historically contributed the least to the problem of anthropogenic climate change. ${ }^{59}$

Already, developing countries are suffering the brunt of climate change impacts. Firm predictions both in terms of human and economic impact are difficult to make with precision, but he general trends are clear. Today, climate change is estimated by some to cause an average of 400,000 deaths per year, over 98 percent of which occur in developing countries. ${ }^{60}$ By 2030 , the total number of climate change-related deaths is predicted to rise significantly, particularly in developing countries. ${ }^{61}$

The economic costs are similarly staggering. In 2010, economic losses attributed to climate change amounted to close to 1 percent of global GDP, or $\$ 700$ billion (2010 PPP). ${ }^{62}$ Developing countries bear an estimated 80 to 90 percent of the total economic costs. ${ }^{63}$ This will have a major impact on these countries' abilities to reach sustainable development goals. In Bangladesh alone, an estimated US\$2.7 billion of the government's development investments are at risk due to climate change. ${ }^{64}$

Among developing countries, Bangladesh stands out both for its exceptional vulnerability to climate change and for its ongoing efforts to adapt to the already serious impacts. Bangladesh has been more active than most in attempting to adapt to climate change. These efforts have taken place both within the UNFCCC's adaptation framework and outside of it. As a result, Bangladesh's experience may offer a good indication of the extent to which the UNFCCC's adaptation efforts are effective.

\section{a. The climate threat to Bangladesh}

Bangladesh has been described as one of the most climate-vulnerable countries in the world. ${ }^{65}$ Most of its land area is low-lying, comprised of the deltaic plains of the Ganges, Brahmaputra and Meghna rivers. Eighty percent of the country is in floodplains and riverbank erosion poses a severe and constant threat. Two-thirds of Bangladesh is less than five metres above sea level, making the country highly

58 Martin Parry, Nigel Arnell, Tony McMichael, Robert Nicholls, Pim Martens, Sari Kovats, Matthew Livermore, Cynthia Rosenzweig, Ana Iglesias and Gunther Fischer, 'Millions at Risk: Defining Critical Climate Change Threats and Targets', 11(3) Global Environmental Change 181 (2011), at 181-183.

59 Robert Mendelsohn, 'The Economics of Adaptation to Climate Change in Developing Countries', 3(2) Climate Change Economics 1 (2012), at 2.

60 Dara and the Climate Vulnerable Forum, Climate Vulnerability Monitor: A Guide to the Cold Calculus of a Hot Planet, 2nd ed, (Spain: Fundacion DARA Internacional, 2012) at 17, 19.

61 Ibid.

62 Ibid.

63 Ibid., at 19.

64 Merylyn Hedger, 'Climate Finance in Bangladesh: Lessons for Development Cooperation and Climate Finance at National Level' (Working Paper No. 12, EDC2020, Bonn, 2011), at 31.

65 Sven Harmeling and David Eckstein, Global Climate Risk Index 2013: Who Suffers Most from Extreme Weather Events? Weather-Related Loss Events in 2011 and 1992 to 2011, (Bonn: Germanwatch e.V., 2012), at 6. 
vulnerable to sea level rise. ${ }^{66}$ Large populations live within the most vulnerable areas, which are also home to a major portion of the Sunderbans, the world's largest single track of mangrove forest. It is estimated that with a $45 \mathrm{~cm}$ sea level rise (which is expected by the year 2050), 75 percent of the Sundarbans will be inundated. ${ }^{67}$ On average, a quarter of the country is inundated by sea-water every year. ${ }^{68}$ In addition, monsoon rains and melting Himalayan glaciers result in annual river flooding. Erratic rainfall exposes the country to severe droughts, particularly in the north and northwestern regions. ${ }^{69}$

Despite being home to hundreds of rivers, access to drinking water is limited. Arsenic contamination of both ground and surface water is a major problem compounded by increased salinity affecting about 20 million coastal residents. ${ }^{70}$ Increased salt-water intrusion is contributing to the top dying of Sundari trees in the Sunderbans and is affecting local fisheries. ${ }^{71}$

The 2013 Global Climate Risk Index lists Bangladesh as having the fourth highest rate of mortality and economic losses due to weather-related events from $1992-2011 .^{72}$ As a result of its direct proximity to the Bay of Bengal, Bangladesh experiences frequent tropical cyclones, and these have had a historically devastating impact on those living close to sea level. Between 1980-2000, more than 250,000 people died as a result of tropical cyclones, with 60 percent of those deaths occurring in Bangladesh. ${ }^{73}$ A 2007 cyclone in southern Bangladesh killed more than 5,000 people.

Climate change is expected to increase the frequency and intensity of many of these events. In a 2013 report, the World Bank characterized Bangladesh as a future impact "hotspot" due to "increasing and compounding challenges occurring in the same timeframe from extreme river floods, more intense tropical cyclones, rising sea

66 Robert J. Nicholls, Poh Poh Wong, Virginia Burkett, Jorge Codignotto, John Hay, Roger McLean, Sachooda Ragoonaden, and Colin D. Woodroffe, 'Coastal Systems and Low-Lying Areas', in Climate Change 2007: Impacts, Adaptation and Vulnerability: Contribution of Working Group II to the Fourth Assessment Report of the Intergovernmental Panel on Climate Change, edited by M.L. Parry, O.F. Canziani, J.P. Palutikof, P.J. van der Linden, and C.E. Hanson (Cambridge: Cambridge University Press, 2007), at 326.

${ }^{67}$ Environment Directorate Development Co-Operation Directorate, Shardul Agrawala, Tomoko Ota, Ahsan Uddin Ahmed, Joel Smith, and Maarten van Aalst, Working Party on Global and Structural Policies, Working Party on Development Co-operation and Environment, Development and Climate Change in Bangladesh: Focus on Coastal Flooding and the Sundarbans, $\mathrm{COM} / \mathrm{ENV} / \mathrm{EPOC} / \mathrm{DCD} / \mathrm{DAC}(2003) 3 /$ FINAL (OECD, 2003), at 19.

68 Aka Firowz Ahmad, Community Based Adaptation to Climate Change in Bangladesh: The Global Initiative at Local Level, online: Monash University < http://www.iec.monash.edu.au/>.

69 N.C. Dey, M.S. Alam, A.K. Sajjan, M.A. Bhuiyan, L. Ghose, Y. Ibaraki and F. Karim, 'Assessing Environmental and Health Impact of Drought in the Northwest Bangladesh', 4(2) Journal of Environmental Science and Natural Resources 89 (2011).

70 The World Bank, Turn Down the Heat: Climate Extremes, Regional Impacts, and the Case for Resilience (Washington, DC: The World Bank, 2013), at 109 (hereinafter World Bank, Turn Down the Heat).

71 Ainun Nishat and Nandan Mukherjee, 'Sea Level Rise and Its Impacts in Coastal Areas of Bangladesh', in Climate Change Adaptation Actions in Bangladesh, edited by Rajib Shaw, Fuad Mallick, and Aminul Islam (Japan: Springer, 2013), at 47.

72 Harmeling and Eckstein, supra note 66, at 6.

73 Nicholls, Wong, Burkett, Codignotto, Hay, McLean, Ragoonaden, and Woodroffe, supra note 67, at 338. 
levels, extraordinarily high temperatures, and declining crop yields." ${ }^{74}$ A combination of more intense tropical cyclones and sea level rise would increase the impact of floods and storm surges, thus reducing arable land. ${ }^{75}$ This will have a serious impact on food production as well as livelihoods, given the fact that two thirds of the workforce is employed in agriculture. ${ }^{76}$ The IPCC has estimated that production of rice and wheat could drop by 8 percent and 32 percent respectively by the year $2050 .{ }^{77}$ Climate migration is expected to increase as people relocate from areas that have become inundated with water. ${ }^{78}$

While Bangladesh is primarily rural, the capital Dhaka is one of the most populated cities in the world. There has been an increasing flow of people from rural areas to the capital in search of better economic prospects and refuge from climate change impacts that have ravaged rural areas. ${ }^{79}$ This has placed a tremendous strain on basic services in Dhaka. Moreover, four flood-prone rivers flank the national capital, and since the majority of the slum and squatter settlements in this city are located in low-lying land areas, they run the risk of being flooded. Waterlogging and inundation, in turn, pose serious health risks. The situation is similar in other cities, such as Chittagong, Khulna, Sylhet, and Rajshahi. ${ }^{80}$

Bangladesh's climate vulnerability is heightened by its low adaptive capacity. Bangladesh remains a poor country, with a per capita GDP of about US\$732. ${ }^{81}$ While recent economic growth may have improved the ability of the government and individuals to pay for adaptation measures, development has also brought environmental degradation and increased climate sensitivity. As well, Bangladesh suffers from weak governance, with corruption endemic in the public sector. ${ }^{82}$ IN short, it is the combination of Bangladesh's low capacity and its high exposure to adverse climate events that makes it particularly vulnerable to climate change.

\section{b. Adaptation Efforts in Bangladesh}

While climate change adaptation is a relatively recent concern for much of the world, the government of Bangladesh has long been active in its attempts to reduce its exposure to adverse climate impacts. The country's experience with devastating tropical cyclones and other weather-related events has helped make climate adaptation a national priority. Since 1974, the government has spent over US\$10 billion (at constant 2007 prices) to increase the country's climate resilience and

74 World Bank, Turn Down the Heat, supra note 71, at 110.

75 Ibid., at 129.

76 Ibid.

77 Nicholls, Wong, Burkett, Codignotto, Hay, McLean, Ragoonaden, and Woodroffe, supra note 67, at 480.

78 World Bank, Turn Down the Heat, supra note 71, at 138.

79 The Brahmaputra and the Jamuna rivers alone have contributed to one million rural inhabitants being driven into poverty, forcing them to relocate, to cities in search of work. Sabina Faiz Rashid, Showkat Gani, and Malabika Sarker, 'Urban Poverty, Climate Change and Health Risks for Slum Dwellers in Bangladesh', in Climate Change Adaptation Actions in Bangladesh, edited by Rajib Shaw, Fuad Mallick, and Aminul Islam (Japan: Springer, 2013), at 57.

80 Ibid., at 59.

81 The World Bank, 2013, GDP Per Capita (Current US\$), online: The World Bank, $<$ data.worldbank.org $>$.

82 Transparency International, 2013, Corruption Perceptions Index 2012, online: TI $<$ http://www.transparency.org/cpi2012/results $>$. 
disaster preparedness. ${ }^{83}$ In 2003, the government established a Comprehensive Disaster Management Programme (CDMP). Now in its second phase, the program aims to reduce vulnerability through an integrated approach to disaster management and climate change. ${ }^{84}$ Climate change concerns have been built into Bangladesh's Coastal Zone Policy, National Water Policy, and Poverty Reduction Strategy. ${ }^{85}$

The country's extreme vulnerability to cyclones, floods, and droughts has helped it become an international leader in dealing with climate change impacts. As a climate hotspot, Bangladesh has been able to benefit from the work and the insights of NGOs and climate researchers already active within the country. ${ }^{86}$ This, along with effective communication between research organizations, government, and civil society has helped spur the country to play an active role within the UNFCCC process. ${ }^{87}$ Bangladesh has participated in all UNFCCC negotiations and chaired the Least Developed Countries (LDC) group from 2004-2006. ${ }^{88}$ As well, the country has contributed multiple IPCC lead authors. ${ }^{89}$

In 2005, Bangladesh became the first country to submit a NAPA to the UNFCCC. ${ }^{90}$ This document identifies priority activities intended to address urgent and immediate adaptation needs. This was followed by the Bangladesh Climate Change Strategy and Action Plan (BCCSAP) in 2008. ${ }^{91}$ The BCCSAP focuses on strategic medium- and long-term actions, and is the key adaptation policy document for the government. In 2010, the government produced the Strategic Program for Climate Resilience (SPCR). The SPCR includes some of the same activities as the NAPA and BCCSAP, but is to be implemented with funding from the World Bank's Climate Investment Funds' Pilot Program for Climate Resilience (PPCR).

Concerned about insufficient funding available under the UNFCCC, the government created two national funds with which to finance its adaptation activities. The Bangladesh Climate Change Trust Fund (BCCTF) is supported entirely by the government's own budget, while the Bangladesh Climate Change Resilience Fund (BCCRF) depends on developed country pledges. Together, the BCCTF and BCCRF have raised more than US\$500 million. ${ }^{92}$

83 Bangladesh, Bangladesh Climate Change Strategy and Action Plan 2009 (Dhaka: Ministry of Environment and Forests, 2009) at xvii (hereinafter BCCSAP).

84 CDMP, Ministry of Disaster Management and Relief, Comprehensive Disaster Management Programme (Phase II), online: CDMP < http://www.cdmp.org.bd/index.php >.

85 Jessica Ayers, Mozaharul Alam and Saleemul Huq, 'Adaptation in Bangladesh', 72 Tiempo 9 (2009), at 11 (hereinafter Ayers, Alam and Huq, 'Adaptation').

86 Ibid., at 10.

87 Ibid.

88 Ibid.

89 Ibid.

90 See generally Bangladesh, Ministry of Environment and Forest, National Adaptation Programme of Action (NAPA), Final Report (November 2005) (hereinafter NAPA 2005).

91 Merylyn Hedger and Golam Rabbani, 'Country-driven Approaches to Climate Finance: Insights from Bangladesh' (GIZ, 2012), at 2.

92 See generally BCCRF, The Bangladesh Climate Change Resilience Fund, online: BCCRF $<$ http://bccrf-bd.org/> (hereinafter BCCRF); see also Bangladesh, Ministry of Environment and Forests, Climate Change Unit, Bangladesh Climate Change Trust Fund, online: Ministry of Environment and Forests $<$ http://www.moef.gov.bd/index.php $>$ (hereinafter $B C C T F)$. 
Outside of strictly adaptation-focused initiatives, adaptation in Bangladesh is also supported by significant amounts of official development assistance (ODA). Increasingly, development partners such as CARE, the World Bank, the Asian Development Bank and the United Nations Development Program are designing projects within which adaptation concerns are "mainstreamed". In many cases, it is difficult to determine to what extent a project is "traditional" ODA, and to what extent it supports adaptation.

The following sections provide a more in-depth look at the key adaptation plans, projects and initiatives in Bangladesh. While it can be difficult to judge the effectiveness of adaptation actions given the inherent uncertainty of future climate conditions, the complexity of adaptation strategies and the lack of easily measurable outputs compared to mitigation, some strengths and weaknesses of the different adaptation elements can nevertheless be observed. Taken together, this can help provide a sense of how effectively adaptation is being supported in Bangladesh, and where improvements need to be made.

\section{i. National Adaptation Programme of Action}

The National Adaptation Programme of Action (NAPA) for Bangladesh was prepared by the country's Ministry of Environment and Forests (MOEF) and submitted to the UNFCCC in $2005 .^{93}$ The NAPA was created following the principles established by the LDC Expert Group, with US\$200,000 contributed by the Least Developed Countries Fund. ${ }^{94}$ Bangladesh was the first country to submit a NAPA. Since then, all of the remaining 47 LDCs have submitted NAPAs.

Bangladesh's NAPA identifies 15 priority adaptation strategies, including coastal afforestation to reduce climate impacts, the provision of drinking water to coastal communities suffering from increased salinity, capacity building for climate change mainstreaming, and the distribution of climate change information to vulnerable communities. The NAPA was updated in 2009 with an additional 45 adaptation measures spread across six thematic areas: research and knowledge management; agriculture, fisheries and livestock; heath; building climate resilient infrastructure; disaster management; livelihood; biodiversity; and policy and institutional capacity building. ${ }^{95}$ Eighteen short- and medium-term projects are identified to help implement these measures. ${ }^{96}$

The first NAPA project to be approved was the 2007 Community Based Adaptation to Climate Change through Coastal Afforestation Program. The project is a partnership between the GEF, which contributed US\$3.3 million from the LDCF, the government, which contributed US\$1 million, and the UNDP, which is implementing the project and contributed a further US\$1 million. ${ }^{97}$ The four-year

93 NAPA 2005, supra note 91.

94 Global Environment Facility (GEF), Detail of GEF Project \#2026, online: GEF <http://www.theg ef.org/gef/project_detail?projID=2026>.

95 Bangladesh, Ministry of Environment and Forest, National Adaptation Programme of Action (NAPA) (Dhaka: Ministry of Environment and Forest, 2009), at 2.

96 Ibid.

97 Global Environment Facility (GEF), Bangladesh - Community-based Adaptation to Climate Change through Coastal Afforestation, online: GEF <http://www.thegef.org/gef/>. 
project aims to reduce the vulnerability of coastal communities through coastal afforestation (which reduces the impact of tidal surges) and the diversification of livelihoods, while strengthening the climate planning capacities of all levels of government, improving the community responsiveness element of coastal management policies and developing a system for collecting, distributing and internalizing climate knowledge. ${ }^{98}$

In 2011, a second NAPA priority project was approved by the GEF. With US\$5.65 million in funding from the LDCF and over US\$40 million in co-funding, this project, entitled Integrating Community-Based Adaptation into Coastal Afforestation and Reforestation Programs in Bangladesh, is a considerable expansion of the earlier afforestation project. ${ }^{99}$ It is designed to further increase resilience through the planting of mangrove and other tree species, the adoption of planting techniques that improve climate resilience, and the increased participation of communities in the management and protection of new greenbelt structures.

To date, these are Bangladesh's only NAPA projects to secure approval and funding from the LDCF, although the UNDP reports that many of the priority adaptation activities have been or are being addressed in ongoing adaptation projects. ${ }^{100}$ To put the support of Bangladesh projects into a broader context, the LDCF has approved 82 projects in developing countries with grants amounting to US $\$ 358$ million. ${ }^{101}$ This represents a small fraction of the priority projects detailed in developing countries' NAPAs, a situation that has led to frustration in many developing countries, not just Bangladesh. ${ }^{102}$ There have also been concerns from a range of actors about the quality of NAPAs, their lack of local and national ownership, and their low status in the wider UNFCCC process. ${ }^{103}$

\section{ii. The Bangladesh Climate Change Strategy and Action Plan}

The MOEF published its key policy framework for addressing climate change, the Bangladesh Climate Change Strategy and Action Plan (BCCSAP) in 2008. The impetus for the BCCSAP was the damage caused by Cyclones Sidr and Aila, and the recognition that a more strategic and coordinated approach to adaptation was needed. ${ }^{104}$ The BCCSAP was designed to help achieve a government strategy for propoor, climate resilient and low carbon development based around the four building blocks of the Bali Action Plan: adaptation, mitigation, technology transfer and

98 Amireeta K. Rawlani and Benjamin K. Sovacool, 'Building Responsiveness to Climate Change through Community Based Adaptation in Bangladesh', 16(8) Mitigation and Adaptation Strategies for Global Change 845 (2011), at 857.

99 UNDP Adaptation Learning Mechanism (ALM), Integrating Community-Based Adaptation into Coastal Afforestation and Reforestation Programs in Bangladesh, online: UNDP-ALM <undp-al m.org>.

100 Adaptation Learning Mechanism (ALM), Country Profile - Bangladesh: Overview, online: ALM $<$ htt p://www.adaptationlearning.net/country-profiles/bd $>$.

${ }^{101}$ Least Developed Countries Expert Group (LEG), Submission Under the Work Programme on Long-term Finance, Decision 4/CP.18, Paragraph 5 (2013), at 3, online: UNFCCC $<$ https://unfccc.int /2860.php>.

102 Asa Persson, 'Institutionalising Climate Adaptation Finance under the UNFCCC and Beyond: Could an Adaptation 'Market' Emerge?' (Working Paper No 2011-03, Stockholm Environment Institute, 2011), at 18.

103 Ibid.

104 Ayers, Alam and Huq, 'Adaptation', supra note 86, at 12. 
adequate and timely flows of investment funds. ${ }^{105}$ It details a 10 -year plan to build capacity and resilience to meet the challenge of climate change over the following 2025 years. ${ }^{106}$ Included is a list of 44 programs designed to be implemented by various ministries.

The BCCSAP is based on six themes: food security, social protection and health; comprehensive disaster management; infrastructure; research and knowledge management; mitigation and low-carbon development; and capacity building and institutional strengthening. ${ }^{107}$ It expands upon Bangladesh's NAPA, while providing more strategic medium- and long-term direction on climate change. The government describes the BCCSAP as a "living document", able to be changed to reflect "new scientific findings, development priorities of the country and the pace and nature of international negotiations." 108 In fact, it has already been updated. It was revised in 2009 after a new government came to power, amid criticisms that the earlier version used international consultants, failed to adequately consult stakeholders, and overemphasized infrastructure. ${ }^{109}$

Bangladesh has been described as "ahead of the game" compared to other developing countries in its preparation of a national climate change strategy. ${ }^{110}$ Still, the BCCSAP has been criticized for not being comprehensive enough. It has been described as a "knowledge strategy", when what is needed is an implementation strategy, with a costed and sequenced delivery framework ${ }^{111}$ and actions prioritized on the basis of vulnerability. ${ }^{112}$ It has been criticized for inadequately considering the role of local governments in facilitating adaptation. ${ }^{113}$ As well, the plan is not backed up with funds or specific laws and policies. ${ }^{114}$

\section{iii. The Bangladesh Climate Change Trust Fund and the Bangladesh Climate Change Resilience Fund}

After preparing the BCCSAP, Bangladesh's government decided that immediate action was needed to implement the plan's activities. ${ }^{115}$ Rather than wait for international finance to arrive, the government elected to create a new fund drawn from the national budget. The first fund of its kind, the Bangladesh Climate Change Trust Fund (BCCTF) allows government and civil society groups to apply for funding

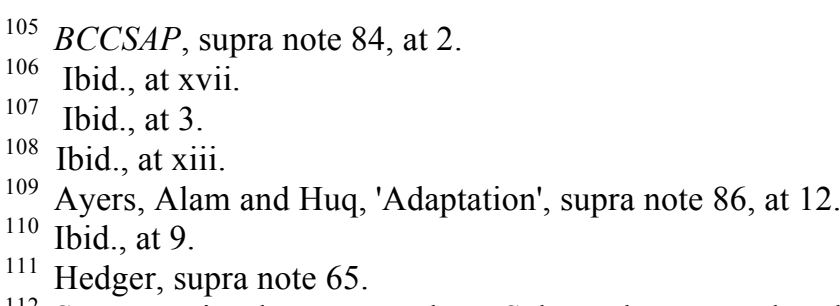

112 S.M. Munjurul Hannan Khan, Saleemul Huq, and Md Shamsuddoha, 'The Bangladesh National Climate Funds: A Brief History and Description of the Bangladesh Climate Change Trust Fund and the Bangladesh Climate Change Resilience Fund' (LDC Paper Series, IIED and ECBI), at 12.

${ }^{113}$ Kevan Christensen, Sajid Raihan, Rubayat Ahsan, A.M. Nasir Uddin, Chowdhury Saleh Ahmed, and Helena Wright, Ensuring Access for the Climate Vulnerable in Bangladesh: Financing Local Adaptation (Dhaka: ActionAid Bangladesh, 2012), at 30.

114 M. Sajid Raihan, M. Jahedul Huq, Nana Gerstrøm Alsted, and Manja Hoppe Andreasen, Understanding Climate Change from Below, Addressing Barriers from Above: Practical Experience and Learning From a Community-based Adaptation Project in Bangladesh (Dhaka: ActionAid Bangladesh, 2010), at 11.

115 Khan, Huq, and Shamsuddoha, supra note 113 , at 3. 
on a project-by-project basis. The BCCTF became operational in 2009 with a US\$100 million budgetary allocation. ${ }^{116}$ This was followed by further allocations in each of the following three years, bringing the total to US $\$ 350$ million as of December $2012 .^{117}$

In 2010, the Climate Change Trust Fund Act was passed. It limits climate change project spending to 66 percent of the BCCTF's resources, with the remainder reserved for emergencies. ${ }^{118}$ So far, more than 100 climate change projects have been approved under the BCCTF, with the highest portion of funding (44 percent) going to infrastructure, and the lowest portion ( 2 percent) spent on capacity building and institutional strengthening. ${ }^{119}$ BCCTF-approved projects have so far covered adaptation, mitigation, technology transfer, research and knowledge management, among other areas. ${ }^{120}$ Projects are approved by a Board of Trustees made up primarily of government ministers, with two spots for civil society organizations. The Board is chaired by the Minister of Environment.

The government recognized from the outset that domestic funding would not be enough to fully support the implementation of the BCCSAP, and that significant international contributions would be needed. ${ }^{121}$ This led to the creation of the Bangladesh Climate Change Resilience Fund (BCCRF). Like the BCCTF, the BCCRF's sole purpose is to finance activities under the BCCSAP, however, in place of domestic sources of funding, the BCCRF is funded through developed country contributions. As of 2013, the fund had raised US $\$ 170$ million. ${ }^{122}$

The BCCRF has approved funding for 10 projects totaling US\$147 million. ${ }^{123}$ Funding decisions are made by a 16-member Governing Council made up of government ministers and representatives from the Prime Minister's Office and Planning Commission, development partners and civil society. ${ }^{124}$ The Minister of Environment acts as Chair. As with the BCCTF, government and civil society can apply for funding on a project basis.

The design and operation of the BCCRF have been controversial. As a precondition to contributing funds, developed countries insisted on a governing role for the World Bank. ${ }^{125}$ This was opposed by civil society groups, and, at least initially, by the government. ${ }^{126}$ Subsequently, the World Bank was granted an interim trusteeship that sees it receive 4.5 percent of the BCCRF's resources as a service charge in return for providing technical assistance, oversight and due diligence. ${ }^{127}$ In 2012, civil society groups protested the World Bank's effort to retain control over the

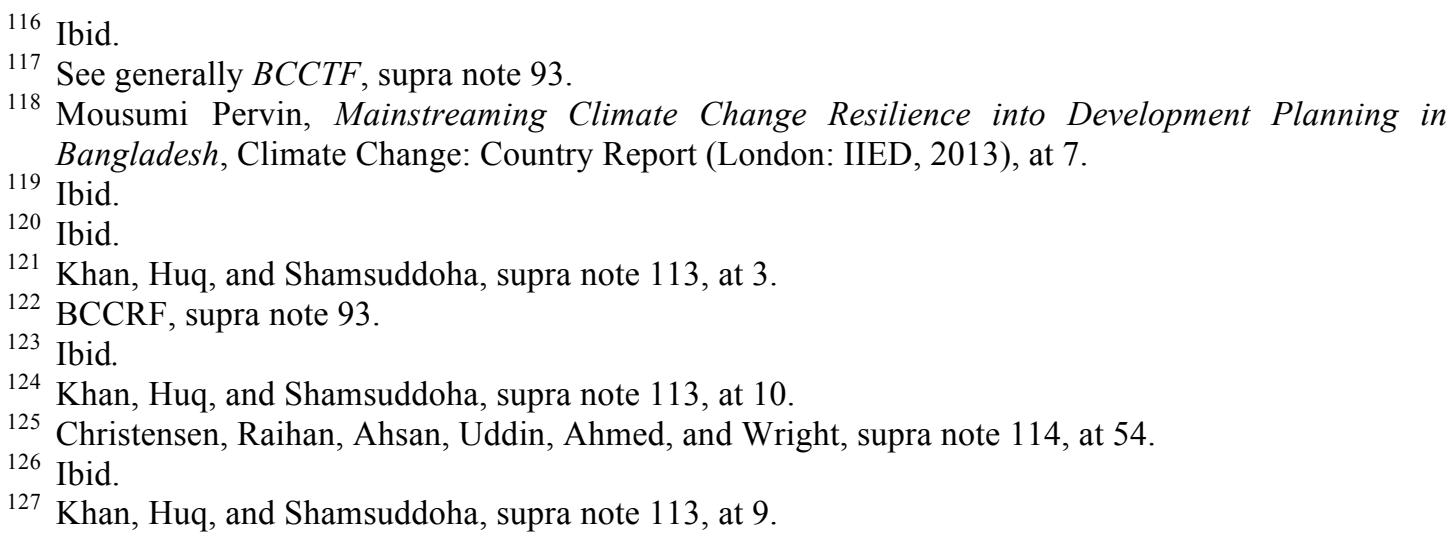


BCCRF instead of transferring control to the government after its interim trusteeship had ended. ${ }^{128}$ The World Bank's governance has been criticized as undemocratic, and concerns have also been raised about the "complex and lengthy" process required to receive funding. ${ }^{129}$

The BCCTF has been subject to criticism. In addition to concerns about the limited funds allocated for capacity building, the fund has faced allegations of corruption and bias in its allocation decisions. ${ }^{130}$ The government has taken some steps to address these allegations through increased civil society oversight. ${ }^{131}$ However, the high proportion of government ministers on the Board of Trustees continues to leave funding decisions vulnerable to undue political influence. ${ }^{132} \mathrm{In}$ some cases, projects have been funded that have no clear link to climate change or that are clearly ineffective or even maladaptive. ${ }^{133}$ Furthermore, local consultations with the people most vulnerable to the effects of climate change have not taken place. $^{134}$

\section{iv. The Strategic Program for Climate Resilience Bangladesh}

In 2010, Bangladesh became one of nine countries (two regions are also included) selected to take part in the Pilot Programme for Climate Resilience (PPCR). The PPCR is a targeted adaptation program of the Strategic Climate Fund (SCF), which is funded through the World Bank-administered Climate Investment Funds (CIF). ${ }^{135}$ The pilot program is intended to help developing countries prepare, implement and finance long-term climate resilience programs that are integrated with the countries' core development planning. ${ }^{136}$ By providing support for country-led, programmatic approaches to adaptation that engage the private sector in order to leverage donor finance, the PPCR aims to go beyond "business as usual" development and provide a new model for global adaptation finance and climate-resistant development. $^{137}$

The Strategic Program for Climate Resilience (SPCR) Bangladesh is Bangladesh's program to implement the PPCR. The SPCR was designed by the government in coordination with the Asian Development Bank (ADB), members of the World Bank Group, key Bangladeshi stakeholders and other development partners. ${ }^{138}$ It is based upon Bangladesh's NAPA and BCCSAP, with projects focused on increasing resilience in three areas: agriculture and food security, coastal embankments and afforestation, and water systems and coastal infrastructure. ${ }^{139}$ The

\footnotetext{
${ }^{128}$ Sam.Lund-Harket, 'Bangladesh Civil Society Protests World Bank Control of Climate Finance', World Development Movement, 22 November 2012, online: WDM < http://www.wdm.org.uk/>.

${ }^{129}$ Christensen, Raihan, Ahsan, Uddin, Ahmed, and Wright, supra note 114, at 54.

${ }^{130}$ Ibid., at 55.

131 Ibid.

132 Khan, Huq, and Shamsuddoha, supra note 113, at 12.

${ }^{133}$ Christensen, Raihan, Ahsan, Uddin, Ahmed, and Wright, supra note 114, at 55.

134 Ibid.

135 The International Institute for Environment and Development (IIED), 'Climate Investment Funds: Understanding the PPCR in Bangladesh and Nepal' (IIED Briefing, London, 2013), at 1 (hereinafter IIED, 'PPCR').

${ }^{136}$ Ibid.

137 Ibid.

${ }_{138}$ Climate Investment Funds (CIF), Pilot Program for Climate Resilience: Bangladesh, (2012), at 1.

139 Ibid., at 2.
} 
SPCR also includes two technical assistance projects. The first, the ADBimplemented "Climate Change Capacity Building and Knowledge Management" project, aims to comprehensively assess Bangladesh's institutional capacity for public and private sector climate resilience planning. ${ }^{140}$ The second, to be implemented by the International Finance Corporation (IFC), is the "Feasibility Study for a Pilot Program of Climate Resilient Housing in the Coastal Region", which looks at potential ways to provide effective, low-cost shelters to protect humans and livestock from cyclone winds and monsoon rains. ${ }^{141}$

The PPCR has provided US\$110 million in grants (45 percent) and near-zero interest credits (55 percent) to help fund the preparation and implementation of the SPCR ${ }^{142}$ It anticipates that Bangladesh will be able to use these funds to leverage an additional US\$461.6 million in private financing. ${ }^{143}$ So far, it has funded seven preparation grants and approved US\$30 million in financing for a coastal resilient infrastructure project. ${ }^{144}$

While the PPCR's innovative approach has been viewed optimistically, its execution has been criticized. In Bangladesh, criticism of the PPCR has stemmed from the influential role given to multilateral development banks and the use of concessional loans to finance adaptation projects. ${ }^{145}$ There has been less stakeholder consultation or buy-in than hoped for (this has been a concern in other PPCR countries as well), ${ }^{146}$ with one or two dominant government ministries able to steer the decision-making process towards projects that reflect their interests. ${ }^{147}$ This has resulted in an emphasis towards large-scale engineering projects, which can sometimes be inappropriate or counterproductive, ${ }^{148}$ rather than a full range of projects that better reflect the entire country's needs. ${ }^{149}$

\section{v. Official Development Assistance}

Bangladesh has been a significant recipient of official development assistance (ODA) for decades. While this aid does not qualify as "new and additional" adaptation finance under the UNFCCC, it has nevertheless become an important part of the effort to build the country's climate resilience. Increasingly, development agencies are integrating climate change considerations into their ODA programs. ${ }^{150}$

\footnotetext{
140 Ibid., at 1.

141 Ibid.

142 Ibid.

143 Ibid.

144 See generally Climate Funds Update, supra note 42.

145 IIED, 'PPCR', supra note 136; see also Hedger, supra note 65, at 28-92.

146 See generally Philip Ireland and Katharine McKinnon, 'Strategic Localism for an Uncertain World: A Postdevelopment Approach to Climate Change Adaptation', 47 Geoforum 158 (2013).

147 IIED, 'PPCR', supra note 136, at 2.

148 Jessica Ayers, Mozaharul Alam and Saleemul Huq, 'Global Adaptation Governance Beyond 2012: Developing Country Perspectives', in Global Climate Governance Beyond 2012: Architecture, Agency and Adaptation, edited by Frank Biermann, Philipp Pattberg and Fariborz Zelli (Cambridge: Cambridge University Press, 2010), at 277.

149 IIED, 'PPCR', supra note 136, at 2.

150 Jessica M. Ayers and Saleemul Huq, 'Supporting Adaptation to Climate Change: What Role for Official Development Assistance?', 27(6) Development Policy Review 675 (2011), at 681.
} 
Ayers and Huq have noted that "more than 60 percent of all ODA could be relevant to building adaptive capacity and facilitating adaptation."151

This creates a dilemma for Banlgadesh. On the one hand, Bangladesh, along with many other developing countries, has pushed to have adaptation assistance under the UNFCCC defined as additional to and separate from ODA in order to ensure that developed countries did not simply neglect their development obligations and reallocate ODA to adaptation assistance. Bangladesh is clear in it position that climate change is an additional stressor, on top of underdevelopment, that is caused by developed countries and that developed countries have an obligation to pay for. ${ }^{152}$

On the other hand, of course, development and adaptation efforts in Bangladesh are interconnected and need to be integrated. According to Ayers and Huq, it is impractical to define adaptation as separate from and additional to development, "given that all adaptation must be underpinned by development objectives that seek to address the underlying causes of vulnerability.", "Standalone' adaptation actions, they argue, cannot be effective when not supported by development. ${ }^{154}$ In short, while it is fair to expect additional funding to assist with adaptation, this should not result in silos that artificially separate development and adaptation.

In Bangladesh, development objectives are integrated into the BCCSAP, and development partners have attempted to align their investments with the action plan. ${ }^{155}$ Capacity building and technical assistance with respect to climate change have been popular development objectives. ${ }^{156}$ However, there have been disagreements between the climate change and development camps with respect to priorities. According to Hedger, the tension is between those who believe climate change to be "the major, priority problem that will undermine development" and those who see it as a "long term issue distracting from urgent problems about hunger and poverty." 157 With comparatively few development partners operating on a wide scale across Bangladesh, synchronization is difficult. ${ }^{158}$

Problems aside, few would question that ODA has a major role to play in helping developing countries increase their resilience to climate change. This means Bangladesh will have to continue to work to ensure that adaptation assistance is additional to ODA, and to develop the capacity to fully integrate its adaptation and ODA initiatives to maximize the resulting impact on both development and climate resilience.

\section{vi. Technology for Adaptation}

\footnotetext{
51 Ibid., at 680.

152 Ahmad, supra note 69, at 13-14.

153 Ayers and Huq, supra note 151, at 688-689.

154 Ibid.

155 Hedger, supra note 65, at 34 .

156 Ibid.

157 Ibid., at 35 .

${ }^{158}$ Hedger and Rabbani, supra note 92, at 3.
} 
Bangladesh is primarily an agrarian nation, with widespread poverty, low levels of literacy and the absence of a technology culture. Despite these limitations, the country has made substantial economic progress in recent years and has developed some basic technologies for climate change adaptation. An important innovation in this regard is "floating gardens", developed in response to a fast vanishing natural resource - land. The technology is one where water hyacinth and bamboo is used to build the base of a raft upon which soil and cow dung is placed and vegetables are grown. These floating gardens have contributed to food security during lean phases, and they are an alternative source of income for the poor. ${ }^{159}$ Given the problem of increasing salinity, Bangladesh is also investing in rainwater harvesting technologies. ${ }^{160}$ These adaptation measures have been small-scale, however, and not of the magnitude required to respond to the severity of the problems posed by climate change impacts.

With external assistance, Bangladesh has been able to develop some higher-end technology-based interventions to promote climate change adaptation. One area where this collaboration has proved fruitful is in the development of early warning systems. Millions in the coastal areas of Bangladesh are exposed to the risk of flooding. Flood forecasts used to be spread through word of mouth and local media, with the consequence that information often arrived late. The Community Flood Information System (CFIS) is a project funded by the United States Agency for International Development and operated by an American company, Riverside Technology, in partnership with the Bangladeshi Center for Environmental and Geographic Information Services and the Bangladesh Disaster Preparedness Centre. It is a five-year project designed to help local communities adapt to floods through a system of flood monitoring and forecasting. ${ }^{161}$ These forecasting technologies have enabled Bangladesh to better prepare itself for floods and other extreme weather events like cyclones, saving lives and reducing destruction to property.

Bangladesh has established a Ministry of Science and Technology, which has the mandate to "make Science and Technology a part of national culture". ${ }^{162}$ There are several institutions under this Ministry including the Bangladesh Council of Scientific and Industrial Research. However these institutions are hamstrung by lack of funds and recently, the emphasis has shifted from climate to information technology.

Importantly, Bangladesh has carried out a technology needs assessment and has prepared technology action plans, identifying agriculture and water sectors as priority areas. These studies identify a number of measures and explore how technologies for adaptation can be utilized. For instance, in relation to the water sector, the needs assessment identifies rehabilitation of embankments/dykes; disaster management incorporating early warning systems; monitoring of sea level rise, tidal fluctuation, salinity intrusion, sedimentation and coastal erosion; tidal river management including computer simulation of tidal flow; tidal barriers (sluice gate), and urban

\footnotetext{
${ }^{159}$ Practical Action, 'Floating Gardens in Bangladesh' (Technical Brief), online: FAO $<\mathrm{http}: / /$ www.fao.o rg $>$.

${ }^{160}$ NAPA 2005, supra note 91, at 20-21.

${ }^{161}$ UNFCCC, Technologies for Adaptation, supra note 12, at 15.

162 Bangladesh, Ministry of Science and Technology, Government of the People's Republic of Bangladesh, online: Ministry of Science and Technology $<\mathrm{http}: / /$ www.mosict.gov.bd $>$.
} 
Infrastructure development. For agriculture, the technology needs assessment identifies the development of salinity-tolerant, drought-tolerant, short-maturing rice varieties; establishment of a climate-smart dissemination center; land use planning; and establishment of a special agricultural R\&D center. ${ }^{163}$ Ultimately, the technology needs assessment emerges as an important management tool that underscores the importance of technology in addressing the adaptation issue, and it helps to formulate strategies for technology development, use and management. ${ }^{164}$

\section{vii. Barriers to Climate Change Adaptation}

There are several barriers that hamper the effective implementation of adaptation actions in Bangladesh. These barriers can be classified into internal and external factors. Significantly, the NAPA identifies lack of awareness of the potential gravity of the problem and possible responses, the inability to mainstream climate change impacts in developing policies, plans and programs in relation to climate sensitive sectors and the lack of adequate tools, knowledge and methodologies to provide guidance and advice to decision makers. ${ }^{165}$ These barriers manifest mainly at the domestic level and can therefore be classified as internal. External barriers relate primarily to difficulties in accessing finance to fund adaptation actions and accessing adaptation relevant technologies.

Bangladesh is a least developed country with serious socio-economic challenges. It has limited financial resources to invest in adaptation actions and local communities have limited adaptive capacities to adjust to climate impacts. ${ }^{166}$ On the human development index, Bangladesh ranks $146 .{ }^{167}$ Since its carbon footprint is negligible, equity demands that developed countries take the lead in providing the financial aid and technology needed to carry out the required adaptation actions. However, as discussed above, the funds available to carry out adaptation fall far short of what is needed to make a perceptible difference on the ground. As well, climate change adaptation has to be mainstreamed into socio-economic policies and projects aimed at eradicating poverty and enhancing quality of life.

Technology plays an important role in carrying out climate change adaptation. Even though Bangladesh has been able to develop technology to support adaptation activities in certain core areas, overall progress has nevertheless been insufficient. In many instances, attempts to implement adaptation have resulted in maladaptation due to lack of access to appropriate technologies. For instance, Bangladesh implemented a coastal embankment project, which produced immediate benefits in terms of bringing more areas under cultivation. As a result of the failure to ensure proper engineering and consideration of the larger environmental implications, within a decade, the

\footnotetext{
${ }^{163}$ See generally Bangladesh, Technology Needs Assessment and Technology Action Plans for Climate Change Adaptation (2012), online: UNFCCC <http://unfccc.int/2860.php $>$.

${ }^{164}$ Of course, the technology needs assessment was part of the UNFCCC effort on technology transfer, an effort that has been under way in parallel with the adaptation effort.

165 NAPA 2005, supra note 91, at 20.

166 At the same time, it should be noted that Bangladesh has managed to sustain economic growth and there has been reduction in poverty since the 1990s. 'Bangladesh and Development: The Path Through the Fields', The Economist, 3 November 2012, online: The Economist $<$ http://www.economist.com/>.

167 UNDP, Human Development Report 2013: The Rise of the South: Human Progress in a Diverse World, UNDP, (New York: UNDP, 2013), at 143.
} 
protection structures became a major cause of waterlogging and drainage congestion, apart from other environmental impacts. ${ }^{168}$

Even though Bangladesh has made rapid strides in producing salt tolerant varieties of rice, which have contributed to food security, the country spends only 0.62 percent of its GDP on research and development. ${ }^{169}$ Consequently, Bangladesh overall has not been able to generate the requisite technologies and in certain cases it lacks the basic science and research and development capacity to internalize and adapt foreign technologies. As well, due to weak institutions and lack of enforcement of intellectual property rights, there is a danger that foreign companies may be discouraged from licensing their technologies. Affected communities may be reluctant to adapt to new technologies and therefore steps may have to be taken to educate and motivate local communities.

Against the backdrop of these barriers we now examine the role of the UNFCCC regime in helping Bangladesh implement appropriate climate change adaptation actions.

\section{HOW THE UNFCCC COULD HELP BANGLADESH}

In order to better protect itself against current and anticipated climate change impacts, Bangladesh requires increased support from the UNFCCC. Support will have to take the form of direct financial assistance and more indirect support to improve the capacity of Bangladesh to turn the financial assistance offered into strong adaptation capacity. Recent negotiations in Doha and Warsaw made little progress on the core issues of adaptation, technology and finance facing Bangladesh. What follows is a list of actions, drawn from the case study and the existing literature, that the UNFCCC would have to take to better protect Bangladesh and, to the extent that the Bangladesh experience is representative, the rest of the world's most vulnerable countries, from the destructive impacts of climate change.

\section{a. Implement stronger mitigation targets}

It is important to recognize at the outset that effective mitigation at a global scale is the only effective way to reduce the adaptation burden on developing countries. The situation in Bangladesh offers a perfect illustration of the need for effective mitigation. Not only is its adaptive capacity low, but there a are clearly limits to the country's ability to adapt to unmitigated climate change, no matter how much effort is made to improve its climate resilience. The impact of sea level rise is perhaps the most obvious example. Much can be done to improve resilience to gradual and moderate sea level rise in Bangladesh. At a certain, point, however, displacement of millions of citizens becomes inevitable.

The more stringent the mitigation targets, the more climate change is avoided, and the more manageable the adaptation challenge in Bangladesh. Additionally, under the Kyoto regime, the more ambitious the targets, the more the flexibility

168 M.Z. Hossain and T. Sakai, 'Severity of Flood Embankments in Bangladesh and Its Remedial Approach', 10 CIGR Journal (2008).

169 See generally Bangladesh, General Economics Division, Planning Commission, Outline Perspective Plan of Bangladesh 2010-2021: Making Vision 2021 A Reality: Final Draft (2010). 
mechanisms are likely to be utilized, which in turn results in increased flow of funds into the Adaptation Fund.

On the other hand, if the UNFCCC continues to set weak mitigation targets, Bangladesh's vulnerability will increase further and the costs of adaptation, and, eventually, loss and damage, will continue to grow. In short, an ambitious, sciencebased mitigation target in the post 2020 regime will be essential, for the sake of mitigation, adaptation and loss and damage.

\section{b. Scale up adaptation finance}

As a participant in the PPCR and a recipient of significant amounts of development aid, Bangladesh already receives more climate-related funding than many other developing countries. However, even though Bangladesh has been very active in the UNFCCC processes, and is clearly recognized as a particularly vulnerable country, the level of funding remains far less than what is required, and moreover, much of it is in the form of loans, rather than grants, and is subject to donor interests. What the country needs most is for the UNFCCC to scale up the level of adaptation finance to better reflect the needs of developing countries.

Bangladesh's experience investing in disaster management has shown that climate-related investments can achieve results. The country's investment of more than US\$10 billion in disaster risk reduction over the past 35 years has helped it reduce its losses from natural disasters. ${ }^{170}$ Effective adaptation, however, requires considerably more funding. The government projected that it would cost US\$5 billion to fund the first five years of the BCCSAP. ${ }^{171}$ It created the BCCTF and BCCRF in part because the UNFCCC financial mechanisms were inadequate. The Adaptation Fund, the LDCF and the SCCF all lack the resources needed to fully support adaptation, and the GCF remains more promise than substance, likely at least until 2020.

The case study illustrates that adequate funding is critical to improving climate resilience in Bangladesh, and that current levels are inadequate. If Bangladesh is to protect itself from the devastating impacts of climate change, and assuming that it is somewhat representative of LDCs, UNFCCC parties need to greatly increase the level of contributions, access new sources of funding, such as those considered in the AGF Report, and ensure that the level of funding committed to adaptation is in the same order of magnitude as that committed to mitigation. ${ }^{172}$

\section{c. Ensure that adaptation funds are used efficiently}

The experience in Bangladesh demonstrates that merely scaling up adaptation finance will not ensure successful adaptation on its own. In Bangladesh, where the level of corruption is among the worst in the world, there is a significant risk that some adaptation funding will not be used effectively. Corruption has already been

\footnotetext{
${ }^{170}$ ESCAP and UNISDR, Reducing Vulnerability and Exposure to Disasters: The Asia-Pacific Disaster Report 2012, (Bangkok: ESCAP, 2012), at 43.

171 BCCSAP, supra note 84 , at 31 .

$172 A G F$, supra note 49.
} 
linked to the selection of projects funded by the BCCTF, and its presence no doubt contributed to donor countries' insistence that the World Bank administer the BCCRF. ${ }^{173}$ Transparency International has noted that climate change adaptation is especially susceptible to misuse of funds due to the fact that adaptation projects often involve construction, a sector that is highly affected by corruption. ${ }^{174}$ In Bangladesh, projects have been funded with no clear link to climate change, wasting scarce funds that could have been put to better use. ${ }^{175}$

In order to prevent adaptation finance from being wasted, the UNFCCC must continue to look for effective ways ensure that strong allocation policies and effective monitoring and reviewing procedures are in place, and it needs to increase support for capacity building in order to help countries such as Bangladesh implement their own policies for ensuring the effective use of funds. It seems clear from the case study that a combination of strong institutions at the UNFCCC and capacity building in Bangladesh will be needed to overcome this challenge.

\section{d. Learn from the PPCR}

The PPCR offers the UNFCCC the opportunity to learn from a significant initiative at tackling climate change adaptation. The PPCR supports long-term programs, rather than the type of projects funded by the UNFCCC, and it encourages private sector investment in ways that might also help to increase funding generated by the UNFCCC. The PPCR will be able to provide the UNFCCC with valuable lessons regarding what works, and what does not work, with respect to climate change adaptation. This could help make up for the fact that a large portion of the PPCR's funding comes from developed countries' Fast Start Finance contributions, monies that the UNFCCC would have rather seen channeled to its own more equitable and democratic climate funds. ${ }^{176}$

\section{e. Technology transfer and support for indigenous technology development}

Given their size and overwhelming dependence on the natural environment for basic needs, developing countries like Bangladesh that are more vulnerable to the negative consequences of climate change need access to a wide variety of technologies in order to effectively adapt. Clearly, technology is a central pillar for successful adaptation. However, private companies in industrialized countries hold intellectual property rights over various adaptation relevant technologies.

The high cost of accessing these technologies can be prohibitive, and they may require further adjustment to be suitable in a developing country context. Since

${ }^{173}$ Christensen, Raihan, Ahsan, Uddin, Ahmed, and Wright, supra note 114, at 54-55.

174 Transparency International, 'Executive Summary' in Global Corruption Report: Climate Change, edited by Gareth Sweeney, Rebecca Dobson, Krina Despota, and Dieter Zinnbauer (London: Earthscan, 2011), at xxxi.

175 Christensen, Raihan, Ahsan, Uddin, Ahmed, and Wright, supra note 114, at 55.

${ }^{176}$ Rebecca Dobson, 'Fast-start Funding: Is There an Emerging Parallel Structure for Climate Finance?' in Global Corruption Report: Climate Change, edited by Gareth Sweeney, Rebecca Dobson, Krina Despota, and Dieter Zinnbauer (London: Earthscan, 2011), at 235-236. 
intellectual property rights are a discrete matter regulated by a different legal regime (namely, the Agreement on Trade Related Aspects of Intellectual Property Rights (TRIPS) which has the potential to facilitate technology transfer), and given that private sector firms expect to be compensated for the use of their patents, the options under the UNFCCC to enhance technology access for adaptation appear somewhat limited.

In light of this, the UNFCCC regime should provide specific financial assistance to developing nations to invest in research and development in critical areas such as the development of new cultivars, creation of climate resilient infrastructure, etc. In other words, the intention should be to promote endogenous capacity in the affected countries by helping them develop technologies most appropriate to their own circumstances. In addition, unless there are changes to intellectual property rights of needed technologies, the UNFCCC will likely have to continue to provide specialized funding to purchase licensing rights for technology relevant to adaptation, and to facilitate their further development to meet the needs of specific countries.

It is clear that states like Bangladesh will have to continue to develop and implement adaptation measures and strategies in areas of water management, protecting coastal zones, creating new climate resilient infrastructure and strengthening existing ones, improving public health, adopting biodiversity conservation measures and improving agriculture. In this regard, the technology needs assessment is an important step. In short, the areas identified by Bangladesh will have to be expanded beyond water and agriculture sectors to include some of the aboveidentified areas. This can help demarcate priority technology needs in a broad spectrum of relevant areas, which in turn can become the source for a portfolio of environmentally sustainable technologies for developing nations, which the UNFCCC can work to ensure that these countries have access to.

Since adaptation is necessarily a country-driven activity, the UNFCCC regime should facilitate the development of an integrated approach that promotes cooperation between the various stakeholders. Such stakeholders include the national and foreign governments, the donor community, bilateral and multilateral institutions, nongovernmental organizations, academic and research institutions, and the private sector. The ultimate objectives would include carrying out technology needs assessments, the creation of mechanisms for technology transfer, creation of enabling environments in the recipient countries and capacity building.

\section{Conclusion}

Despite fiscal and technological constraints and the uncertainty associated with climate change impacts, Bangladesh has recognized the urgent need to adapt to climate change. The adoption of the Bangladesh Climate Change Strategy and the Action Plan stand testimony to its resolve. However, given the inherent limitations that Bangladesh and similarly situated poverty-stricken countries face, and the fact that these countries have contributed least to the problem of climate change, there is a need for a higher scale of support from the UNFCCC regime, if these countries are to effectively adapt to climate change impacts. 
Two aspects emerge as critical. The first is the availability of sufficient funds for climate change adaptation that can help nations implement climate change adaptation actions, including mainstreaming of these measures into national development activities. The second relates to the transfer and development of suitable environmentally sound technologies to which developing countries currently do not have access, such as the development of new cultivars that are able to withstand climate vagaries, technology to implement climate proofing, creation of climateresilient infrastructure like polders and sea walls in the coastal regions, ensuring the construction of all weather roads to ensure connectivity, etc.

The UNFCCC regime emerges as a platform that needs to reduce the cleft between developed and developing countries regarding mitigation and adaptation obligations and helps create synergies between the financing of climate change adaptation actions and technology transfer to implement adaptation actions. However, this cannot be a one-track affair, contingent solely on what the UNFCCC regime can offer developing countries. Rather, Bangladesh, with the support of the UNFCCC, will have to strengthen its governance mechanisms and institutional frameworks, create enabling environments and develop its absorptive capacity in order to ensure that the financial and technological benefits derived from the UNFCCC regime reach the real beneficiaries at the local level and are not wasted. Ultimately, to succeed, adaptation has to be pinned down to local circumstances, involving local inputs, planning and implementation. 